\title{
A Polymorphism in the Gene Encoding the Insulin Receptor Binding Protein ENPP-1 Is Associated with Decreased Glomerular Filtration Rate in an Under-Investigated Indigenous African Population
}

\author{
Eleanor M. Cave ${ }^{a} \quad$ Katherine L. Prigge ${ }^{a, b} \quad$ Nigel J. Crowther ${ }^{a, b}$ \\ Jaya A. George ${ }^{a, b}$ Carolyn J. Padoa ${ }^{a, b}$ \\ aDepartment of Chemical Pathology, University of the Witwatersrand Faculty of Health \\ Sciences, Johannesburg, South Africa; ${ }^{b}$ National Health Laboratory Service University of the \\ Witwatersrand, Johannesburg, South Africa
}

\author{
Keywords \\ Polymorphism - Glomerular filtration rate · Ectonucleotide pyrophosphatase/ \\ phosphodiesterase $1 \cdot$ rs 1044498
}

\begin{abstract}
Introduction: The C allele of the ectonucleotide pyrophosphatase/phosphodiesterase 1 (ENPP-1) rs 1044498 polymorphism has previously been associated with increased binding of ENPP-1 to the insulin receptor (IR), resulting in decreased IR signalling and enhanced insulin resistance. It has also been associated with reduced kidney function in participants with diabetes of predominantly European and Asian descent. The association of this polymorphism with kidney disease in healthy Black South African participants has yet to be ascertained. $\mathbf{O b}$ jective: This study, therefore, aimed to determine whether the $\mathrm{K} 121 \mathrm{Q}$ polymorphism is associated with estimated glomerular filtration rate (eGFR) in a Black South African cohort. Methods: Black South African participants $(n=348)$ from an existing cohort with known eGFR levels were genotyped for the K121Q polymorphism using PCR-RFLP and assessed for any statistical association between genotype and kidney function. Results: Individuals with the A allele had significantly lower eGFR levels than individuals with the CC genotype (86.52 \pm 18.95 vs. $93.29 \pm 23.55 \mathrm{~mL} / \mathrm{min} ; p=0.022$ ). The association of the A allele with lower eGFR levels remained after controlling for sex, blood pressure, insulin resistance, age, smoking, thyroidstimulating hormone, insulin-like growth factor -1 , and $\mathrm{BMI}\left(R^{2}=0.030, p<0.001\right)$. Conclusion: The rs1044498 A allele was significantly associated with lower eGFR levels in a cohort of apparently healthy Black South Africans, through an unknown mechanism that was independent
\end{abstract}


of insulin resistance. It is possible that the rs1044498 polymorphism affects kidney function by altering the role of ENPP-1 in endothelial wound healing, podocyte signalling, or oxidative stress. Thus, the presence of this polymorphism may predispose individuals to a greater risk of CKD even in the absence of diabetes.

\section{Introduction}

Ectonucleotide pyrophosphatase/phosphodiesterase 1 (ENPP-1) is a transmembrane glycoprotein, which is known to bind the insulin receptor (IR) [1]. In addition, ENPP-1 functions to generate inorganic pyrophosphate from adenosine triphosphate and dinucleotide polyphosphates and plays an important role in bone mineralization [2]. An ENPP-1 nonsynonymous A > C polymorphism (rs1044498) located in the protein binding region, imparts an amino acid change of lysine (K) to glutamine (Q) at codon 121 (K121Q, also known as K173Q). This amino acid change enhances ENPP-1 binding to the IR, which inhibits receptor signalling [3]. The presence of the $Q$ allele has previously been associated with insulin resistance, type 2 diabetes, and obesity [4-6]. However, not all studies have shown these associations suggesting that the effect may be small or due to the presence of other polymorphisms [7-13].

The ENPP-1 protein is known to be expressed, alongside the IR, within the epithelial cells of the kidney tubules [14]. Thus, ENPP-1 and the K121Q polymorphism may be important in kidney function. It has been hypothesized that as the $Q$ variant causes insulin resistance; the resultant hyperinsulinemia would lead to increased reabsorption of sodium. This, in turn, would result in the upregulation of the angiotensin II type I receptor, which causes reduced vasodilation and, therefore, increased blood pressure, the leading cause of kidney disease [15].

The K121Q polymorphism has been associated with decreased kidney function in individuals with diabetes (both type 1 and type 2) [15-19]; however, these studies were carried out in Caucasian and Asian populations. A single study looking at Brazilian individuals of selfreported African ancestry showed no association [11].

Despite evidence that the K121Q polymorphism is associated with decreased kidney function in participants with diabetes, the effect of this polymorphism on kidney function in a non-diabetic population has not been investigated. Therefore, this study aimed to determine the effect of the K121Q polymorphism on kidney function in a Black South African cohort.

\section{Methods}

\section{Study Participants}

A cohort of 348 Black South African participants (18-67 years of age; self-reported ethnicity) were selected from a larger study carried out in the greater Johannesburg-Soweto metropolitan area as described by George et al. [20]. Estimated glomerular filtration rate (eGFR) was calculated for all participants using a modified modification of diet in renal disease formula which has previously been validated within the South African population and is commonly used within South African laboratories [21]. Systolic (SBP) and diastolic blood pressure (DBP) measurements were available for all participants, as were thyroid-stimulating hormone (TSH), insulin, and insulin-like growth factor-1 (IGF-1) serum levels. Weight, height, and BMI were measured in all participants. Homeostatic model assessment of insulin resistance (HOMA-IR) was determined for all participants. The smoking habits of all partici-

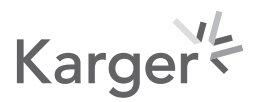


pants were assessed, and each individual was defined as either a current smoker or a current nonsmoker. The methods of measurement for all these variables have been described in detail elsewhere [20]. Ethics clearance was obtained from the Human Research Ethics Committee of the University of the Witwatersrand (ethics clearance number M10411 and M150882).

\section{Genotyping}

All participants were genotyped for the K121Q polymorphism (rs1044498) using PCR-RFLP as previously described [22, 23]. Briefly, the region of the ENPP-1 gene flanking the polymorphism was amplified using Phusion High-Fidelity DNA Polymerase (New England Biolabs, Ipswich, MA, USA) and the PCR products digested with AvaII (New England Biolabs, Ipswich, MA, USA).

\section{Statistical Analysis}

$\mathrm{A} \chi^{2}$ test was performed to confirm that the genotype frequencies were in Hardy Weinberg equilibrium. The CA and AA genotype were combined for analysis as the AA genotype alone was found at a frequency which was too low to analyse separately $(n=2)$. Normally, distributed continuous variables were represented as mean \pm standard deviation whilst skewed data were represented by median (interquartile range), and 95\% confidence intervals (95\% CIs) were calculated for both. Skewed data were log transformed to normality with the exception of BMI for which the reciprocal was used to obtain normality. The 2-tailed Student's nonpaired $t$ test was used to compare the mean variable levels between the 2 genotypic groups (CC vs. CA/AA). Results were determined to be significant if the $p$ value $<0.05$. A multivariable linear regression analysis was performed using eGFR as the dependent variable to determine if the effect of the K121Q genotype was retained after adjusting for possible confounders, that is, BMI, age, HOMA-IR, TSH, IGF-1, DBP, SBP, gender, and smoking. These variables were adjusted for as they have previously been associated with kidney function in the literature [15, 24-29]. All statistical analyses were performed using Statistica software version 13 (StatSoft, Tulsa, OK, USA).

\section{Results}

The characteristics of the study population are represented in Table 1. The cohort was matched for gender (47.4 male vs. $52.6 \%$ female; $p=0.495$ ). The median age of the cohort was 42.0 [22.0] years and the mean eGFR was $91.8 \pm 22.8 \mathrm{~mL} / \mathrm{min}$. Within the cohort, $48.3 \%$ of individuals had an eGFR $\geq 90 \mathrm{~mL} / \mathrm{min}, 47.1 \%$ had an eGFR between 60 and $89 \mathrm{~mL} / \mathrm{min}$, and $4.6 \%$ had an eGFR $<60 \mathrm{~mL} / \mathrm{min}$.

The genotypic and allelic percentages of rs1044498 are shown in Table 2. The ENPP-1 K121Q polymorphism was found to be in Hardy Weinberg equilibrium with a minor allele frequency (A) of 0.11 .

Variables were compared between individuals with the CC genotype and those with either the AA or CA genotype (Table 3). Individuals with the CA/AA genotypes had significantly lower eGFR levels than those with the CC genotype (86.52 \pm 18.95 vs. $93.29 \pm 23.55$ $\mathrm{mL} / \mathrm{min} ; p=0.022$ ). No other variables showed any significant difference between the 2 genotype groups. Only 2 participants were found to be homozygous for the A allele with eGFR values of 101.5 and $92.6 \mathrm{~mL} / \mathrm{min}$, compared to the mean eGFR values for participants with the CC genotype of $93.3 \pm 23.6$ and the CA genotype of $88.9 \pm 20.0 \mathrm{~mL} / \mathrm{min}$. To confirm that the eGFR values for participants with the AA genotype did not influence the results, we removed these participants from the analysis. The heterozygous genotype remained signifi-

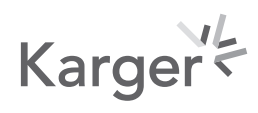


Kidney and

Blood Pressure

Research

Table 1. General characteristics of the study population

\begin{tabular}{|c|c|c|}
\hline \multicolumn{3}{|c|}{ Kidney Blood Press Res 2020;45:1009-1017 } \\
\hline DOI: $10.1159 / 000511213$ & \multicolumn{2}{|c|}{$\begin{array}{l}\text { (c) } 2020 \text { The Author(s). Published by S. Karger AG, Basel } \\
\text { www.karger.com/kbr }\end{array}$} \\
\hline \multicolumn{3}{|c|}{$\begin{array}{l}\text { Cave et al.: The ENPP-1 K121Q Polymorphism Association with eGFR in a South Africar } \\
\text { Cohort }\end{array}$} \\
\hline Variables & $N$ & Value \\
\hline Age, years & 348 & $42.0[22.50]$ \\
\hline Gender ( $\%$ male; $n$ male $)$ & 348 & $47.4(165)$ \\
\hline eGFR, $\mathrm{mL} / \mathrm{min}$ & 348 & $91.8 \pm 22.8$ \\
\hline TSH, mIU/L & 345 & $1.8[1.4]$ \\
\hline $\mathrm{SBP}, \mathrm{mm} \mathrm{Hg}$ & 345 & $131.0[25.0]$ \\
\hline $\mathrm{DBP}, \mathrm{mm} \mathrm{Hg}$ & 345 & $83.0[16.0]$ \\
\hline BMI, $\mathrm{kg} / \mathrm{m}^{2}$ & 348 & $26.0[11.1]$ \\
\hline HOMA-IR & 348 & $1.8[1.8]$ \\
\hline Insulin, mU/L & 348 & $7.71[7.32]$ \\
\hline IGF-1, $\mu \mathrm{g} / \mathrm{L}$ & 348 & $146.5[98.0]$ \\
\hline Smoking $(\% ; n$ smokers $)$ & 345 & $34.5(119)$ \\
\hline
\end{tabular}

Normal data represented as mean \pm standard deviation, skewed data represented by median [interquartile range], and categorical data represented by percentage (numerator). eGFR, estimated glomerular filtration rate; TSH, thyroid-stimulating hormone; SBP, systolic blood pressure; DBP, diastolic blood pressure; HOMA-IR, homeostatic model assessment of insulin resistance; IGF, insulin-like growth factor.
Table 2. Genotypic and allelic percentages of rs1044498 in 348 Black South African study participants

\begin{tabular}{|c|c|c|c|c|}
\hline \multicolumn{3}{|c|}{ Genotype percentage } & \multicolumn{2}{|c|}{ Allele percentage } \\
\hline $\mathrm{CC}(n=272)$ & $\mathrm{CA}(n=74)$ & $\mathrm{AA}(n=2)$ & $\mathrm{C}(n=618)$ & $\mathrm{A}(n=78)$ \\
\hline 78 & 21 & 1 & 89 & 11 \\
\hline
\end{tabular}


Kidney and

Blood Pressure

Research

Table 4. Multivariable linear regression for determinants of eGFR in a South African Black population

\begin{tabular}{|c|c|c|c|}
\hline \multicolumn{4}{|c|}{ Kidney Blood Press Res 2020;45:1009-1017 } \\
\hline DOI: $10.1159 / 000511213$ & \multicolumn{3}{|c|}{$\begin{array}{l}\text { (c) } 2020 \text { The Author(s). Published by S. Karger AG, Basel } \\
\text { www.karger.com/kbr }\end{array}$} \\
\hline \multicolumn{4}{|c|}{$\begin{array}{l}\text { Cave et al.: The ENPP-1 K121Q Polymorphism Association with eGFR in a South African } \\
\text { Cohort }\end{array}$} \\
\hline Dependent variable & Independent variable & $b$ value & $p$ value \\
\hline \multirow[t]{10}{*}{ eGFR } & $\operatorname{Sex}^{\mathrm{a}}$ & 5.86 & 0.024 \\
\hline & Age & 1.00 & $<0.001$ \\
\hline & Smoking ${ }^{b}$ & -9.79 & $<0.001$ \\
\hline & Genotype coding ${ }^{\mathrm{c}}$ & -5.92 & 0.021 \\
\hline & IGF-1 & 0.06 & $<0.001$ \\
\hline & SBP & 0.00 & 0.954 \\
\hline & BMI & 0.25 & 0.219 \\
\hline & DBP & -0.07 & 0.565 \\
\hline & TSH & 0.32 & 0.728 \\
\hline & HOMA-IR & -0.24 & 0.664 \\
\hline
\end{tabular}

IGF, insulin-like growth factor; SBP, systolic blood pressure; DBP, diastolic blood pressure; TSH, thyroid-stimulating hormone; HOMA-IR, homeostatic model assessment of insulin resistance. ${ }^{\text {a }}$ Gender code, $1=$ male and $0=$ female. ${ }^{\mathrm{b}}$ Smoking code, $1=$ smoker and $0=$ nonsmoker. ${ }^{\mathrm{c}}$ Genotype coding, $0=\mathrm{CC}$, and 1 = CA/AA; for full model, unadjusted $R^{2}=0.30, p<0.001(n=344)$.

cantly associated with lower eGFR levels (see online suppl. Table 1; for all online suppl. material, see www.karger.com/doi/10.1159/000511213).

The association of genotype with eGFR was confirmed through regression analysis taking into account the effect of gender, age, smoking status, IGF-1, blood pressure, HOMA-IR, BMI, and TSH (Table 4). The resultant model accounted for $30 \%$ of eGFR variability. The model demonstrated that eGFR in females was $5.86 \mathrm{~mL} / \mathrm{min}$ lower than in males whilst a $1 \mu \mathrm{g} / \mathrm{L}$ increase in IGF-1 was associated with a $0.06 \mathrm{~mL} / \mathrm{min}$ fall in eGFR, and a 1-year increase in age was associated with a $1.00 \mathrm{~mL} / \mathrm{min}$ fall in eGFR. Participants who smoked had eGFR that was $9.79 \mathrm{~mL} / \mathrm{min}$ lower than nonsmokers, whilst individuals with the CA/AA genotype had eGFR that was $5.92 \mathrm{~mL} / \mathrm{min}$ lower than those with the CC genotype. In addition, when the 2 participants with the AA genotype were removed from the analysis, individuals with the CA genotype had eGFR $6.09 \mathrm{~mL} / \mathrm{min}$ lower than those with the CC genotype (online suppl. Table 2).

\section{Discussion}

In the current study, the presence of the A allele of the K121Q polymorphism within the ENPP-1 gene is associated with reduced eGFR in the South African Black population. To our knowledge, only 2 studies on the association of the K121Q polymorphism with kidney function have been carried out in populations of African descent. A study carried out in a Brazilian population of type 2 diabetic participants subgrouped into those with African or European ancestry, found that in both groups individuals carrying the A allele had the highest prevalence of microalbuminuria [11], although the association was not statistically significant. These data are similar to that seen in our cohort where individuals heterozygous for the ENPP-1 polymorphism (CA) had significantly lower eGFR levels. In contrast, a study conducted in African Americans with type 2 diabetes did not show any association of the K121Q polymorphism with kidney function; however, they did show an association between renal disease and the distal region of the ENPP-1 gene [30]. The frequency of the Q allele (which corresponds to the $\mathrm{C}$ allele) in the participants of African ancestry in the Brazilian study (0.50) [11] was significantly lower than that seen in the 1,000 genomes project for sub-Saharan African 
populations (0.88) [31], as well as that seen in our study (0.89). The frequency of the C allele in the study performed in African Americans was 0.79 [30]. Given the large proportion of genetic admixture in the Brazilian population, it is likely that many of these participants were of mixed ancestry [11,32]. In addition, African Americans are known to have approximately a quarter of non-African ancestry [33]. Therefore, these studies may not be a true representation of an African population. It should be noted that in European populations the frequency of the $C$ allele $(0.10-0.21)$ is much lower than that observed in African populations $[11,31]$.

Studies performed in populations of European or Asian ancestry have shown that the $\mathrm{C}$ allele of the K121Q polymorphism is associated with kidney dysfunction in diabetic participants [15-18], whereas the current study shows that the A allele is associated with lower eGFR levels in non-diabetic African subjects. It is possible that this discrepancy could be due to the K121Q polymorphism being transferred in linkage disequilibrium with the actual causative variant in a pattern that differs between these populations. It is possible that the causal variant is located in the distal regions of the ENPP-1 gene as described by Keene and colleagues [30]. It is also interesting to note that in both European and Asian populations, the minor allele is $C$ whilst in African populations it is A [11,31]. Alternatively, our data may differ from the previous studies as they were conducted in cohorts consisting of individuals with diabetes [15-18]. It has been suggested that the association of the 121Q variant with poor kidney function is due to its association with insulin resistance $[5,16]$. Thus, it is possible that in diabetic participants in whom insulin resistance is very prevalent; the association of the $C$ allele with reduced kidney function is mediated by insulin resistance, thus, masking the effect of the A allele. In the present study, we controlled for the impact of insulin resistance, BMI, and blood pressure and found that the A polymorphism was independently associated with low eGFR levels.

Recently, it has been shown that ENPP-1 is important in wound healing and maintaining the epithelial barrier in the intestine [34]. It is known that the epithelium of the renal tubule (where ENPP-1 is located) and that of the intestine are architecturally similar [35, 36], thus, the mechanism within the intestine may be reflected in the kidney. Within the intestine, ENPP-1 expression has been shown to correlate with the expression of claudin- 1 (which is also located within the renal tubules) [34,37]. It is thought that renal tubular injury may be responsible for driving CKD [38]. It is, therefore, possible that decreased kidney healing through a change in the ENPP-1 protein may influence the development of kidney disease, resulting in lower GFR. The ENPP-1 gene is also expressed in rodent podocytes, where it may play a role in signal transduction [39]. Podocytes play an important role in the control of GFR, and therefore, any alteration in ENPP-1 activity in these cells may affect renal function. A further mechanism by which ENPP-1 may modulate GFR is via the action of the transcription factor nuclear factor erythroid 2-related factor 2 (NRF2). It is known that in bone ENPP-1 generates pyrophosphate which is hydrolyzed by alkaline phosphatase to phosphate. Phosphate activates bone mineralization by stimulating the expression of a host of proteins that control the mineralization process, including NRF2 [40]. Studies have shown that NRF2 is expressed in renal tissue where it reduces oxidative stress, a process that is known to be an aetiological factor in a number of different kidney diseases [41]. Thus, reduced ENPP-1 function may lead to a lower expression of NRF2 and, hence, limited capacity of renal tissue to attenuate the levels of reactive oxygen species. The effect that the K121Q polymorphism may have on renal function has not been fully elucidated, and further, studies are required to determine whether ENPP-1 dysfunction may cause renal pathology, and the molecular pathways involved.

There were some limitations to our study. Only 2 individuals were homozygous for the A allele, and therefore, we were unable to analyse the effect of the homozygous AA genotype. The participants with the AA genotype, however, appeared to have eGFR values that were

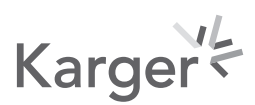


higher than the heterozygotic group and more similar to those with the CC genotype. This may be a chance event, or alternatively, this may be an example of underdominance where the heterozygous genotype mediates a significant negative effect on the phenotype when compared to either homozygous genotype. Such effects have been reported in previous human gene association studies [42]. Thus, underdominance would need to be confirmed in a larger study population. In addition, we utilized eGFR values to assess renal function, rather than using the gold standard method of GFR assessment, inulin clearance [43]. It is known that both analytical and biological factors can affect serum creatinine levels and, thus, the eGFR value [44]. In conclusion, the CA/AA genotype of the K121Q polymorphism in the ENPP-1 gene is associated with decreased eGFR in the Black South African population and may predispose this population to an increased risk of kidney disease through a mechanism that is independent of insulin resistance.

\section{Acknowledgements}

We would like to acknowledge the study participants who made this work possible and the staff of the Chemical Pathology routine laboratory at Charlotte Maxeke Johannesburg Academic Hospital who performed the measurements of the blood analytes.

\section{Statement of Ethics}

Ethics clearance was obtained from the University of the Witwatersrand Human Research Ethics Committee (M10411 and M150882). All participants gave written informed consent to participate in this study.

\section{Conflict of Interest Statement}

The authors have no conflicts of interest to declare. E.M.C. is employed by the University of the Witwatersrand. K.L.P., C.J.P., N.J.C., and J.A.G. are employed by the National Health Laboratory Service.

\section{Funding Sources}

This work was supported by the National Health Laboratory Service Research Trust, South Africa. The research trust was not involved in data generation or manuscript writing/ editing. Biochemical analysis was funded by a self-initiated grant from the Medical Research Council of South Africa and a Carnegie Large Grant.

\section{Author Contributions}

E.M.C.: conceptualization; formal analysis; funding acquisition; investigation; and writing - original draft. K.L.P.: conceptualization; formal analysis; investigation; and writing - original draft. N.J.C.: formal analysis and writing - review and editing. J.A.G.: funding acquisition; investigation; and writing - review and editing. C.J.P.: formal analysis; investigation; and writing - original draft. 


\section{References}

1 Liang J, Fu M, Ciociola E, Chandalia M, Abate N. Role of ENPP1 on adipocyte maturation. PLoS One. 2007;2(9): e882.

2 Ermakov S, Toliat MR, Cohen Z, Malkin I, Altmüller J, Livshits G, et al. Association of ALPL and ENPP1 gene polymorphisms with bone strength related skeletal traits in a Chuvashian population. Bone. 2010 May;46(5): 1244-50.

3 Goldfine ID, Maddux BA, Youngren JF, Reaven G, Accili D, Trischitta V, et al. The role of membrane glycoprotein plasma cell antigen 1/ectonucleotide pyrophosphatase phosphodiesterase 1 in the pathogenesis of insulin resistance and related abnormalities. Endocr Rev. 2008 Feb;29(1):62-75.

4 Pizzuti A, Frittitta L, Argiolas A, Baratta R, Goldfine ID, Bozzali M, et al. A polymorphism (K121Q) of the human glycoprotein PC-1 gene coding region is strongly associated with insulin resistance. Diabetes. 1999 Sep;48(9): 1881-4.

5 Abate N, Carulli L, Cabo-Chan A Jr, Chandalia M, Snell PG, Grundy SM. Genetic polymorphism PC-1 K121Q and ethnic susceptibility to insulin resistance. J Clin Endocrinol Metab. 2003 Dec;88(12):5927-34.

6 Bottcher Y, Korner A, Reinehr T, Enigk B, Kiess W, Stumvoll M, et al. ENPP1 variants and haplotypes predispose to early onset obesity and impaired glucose and insulin metabolism in German obese children. J Clin Endocrinol Metab. 2006 Dec;91(12):4948-52.

7 Rasmussen SK, Urhammer SA, Pizzuti A, Echwald SM, Ekstrøm CT, Hansen L, et al. The K121Q variant of the human PC-1 gene is not associated with insulin resistance or type 2 diabetes among Danish caucasians. Diabetes. 2000 Sep;49(9):1608-11.

8 Gonzalez-Sanchez JL, Martinez-Larrad MT, Fernandez-Perez C, Kubaszek A, Laakso M, Serrano-Rios M. K121Q PC-1 gene polymorphism is not associated with insulin resistance in a Spanish population. Obes Res. 2003 May;11(5):603-5.

9 Morrison JA, Gruppo R, Glueck CJ, Stroop D, Fontaine RN, Wang P, et al. Population-specific alleles: the polymorphism (K121Q) of the human glycoprotein PC-1 gene is strongly associated with race but not with insulin resistance in black and white children. Metab Clin Exp. 2004 Apr;53(4):465-8.

10 Lyon HN, Florez JC, Bersaglieri T, Saxena R, Winckler W, Almgren P, et al. Common variants in the ENPP1 gene are not reproducibly associated with diabetes or obesity. Diabetes. 2006 Nov;55(11):3180-4

11 Leitao CB, Nabinger GB, Krahe AL, Bolson PB, Gerchman F, Friedman R, et al. The role of K121Q ENPP1 polymorphism in diabetes mellitus and its complications. Braz J Med Biol Res. 2008 Mar;41(3):229-34.

12 Shi X, Wang L, Jin F, Sun J, Sun L, Tang L, et al. The ENPP1 K121Q polymorphism is not associated with type 2 diabetes in northern Chinese. Acta Diabetol. 2011 Dec;48(4):303-10.

13 Albegali AA, Shahzad M, Ullah MI, Mahmood S, Rashid M. Association of genetic polymorphism of PC-1 gene (rs1044498 Lys121Gln) with insulin-resistant type 2 diabetes mellitus in Punjabi Population of Pakistan. Mol Genet Genomic Med. 2019 Aug;7(8):e775.

14 Pandey G, Makhija E, George N, Chakravarti B, Godbole MM, Ecelbarger CM, et al. Insulin regulates nitric oxide production in the kidney collecting duct cells. J Biol Chem. 2015 Feb 27;290(9):5582-91.

15 Canani LH, Ng DP, Smiles A, Rogus JJ, Warram JH, Krolewski AS. Polymorphism in ecto-nucleotide pyrophosphatase/phosphodiesterase 1 gene (ENPP1/PC-1) and early development of advanced diabetic nephropathy in type 1 diabetes. Diabetes. 2002 Apr;51(4):1188-93.

16 De Cosmo S, Minenna A, Zhang YY, Thompson R, Thompson R, Miscio G, et al. Association of the Q121 variant of ENPP1 gene with decreased kidney function among patients with type 2 diabetes. Am J Kidney Dis. 2009 Feb;53(2):273-80.

17 Wu LS, Hsieh CH, Pei D, Hung YJ, Kuo SW, Lin E. Association and interaction analyses of genetic variants in ADIPOQ, ENPP1, GHSR, PPARgamma and TCF7L2 genes for diabetic nephropathy in a Taiwanese population with type 2 diabetes. Nephrol Dial Transplant. 2009 Nov;24(11):3360-6.

18 Lin CC, Wu CT, Wu LS. Ectonucleotide pyrophosphatase/phosphodiesterase $1 \mathrm{~K} 173 \mathrm{Q}$ polymorphism is associated with diabetic nephropathy in the Taiwanese population. Genet Test Mol Biomarkers. 2011 Apr;15(4): 239-42.

19 Sortica DA, Buffon MP, Souza BM, Nicoletto BB, Santer A, Assmann TS, et al. Association between the ENPP1 K121Q polymorphism and risk of diabetic kidney disease: a systematic review and meta-analysis. PLoS One. 2015;10(3):e0118416.

20 George JA, Norris SA, van Deventer HE, Crowther NJ. The association of 25 hydroxyvitamin D and parathyroid hormone with metabolic syndrome in two ethnic groups in South Africa. PLoS One. 2013;8(4):e61282.

21 van Deventer HE, George JA, Paiker JE, Becker PJ, Katz IJ. Estimating glomerular filtration rate in black South Africans by use of the modification of diet in renal disease and Cockcroft-Gault equations. Clin Chem. 2008 Jul; 54(7):1197-202.

22 Santoro N, Cirillo G, Lepore MG, Palma A, Amato A, Savarese P, et al. Effect of the rs 997509 polymorphism on the association between ectonucleotide pyrophosphatase phosphodiesterase 1 and metabolic syndrome and impaired glucose tolerance in childhood obesity. J Clin Endocrinol Metab. 2009 Jan;94(1):300-5.

23 Cave E, Prigge K, Padoa CJ, Crowther NJ, George JA. Gender-specific association of the K121Q ectonucleotide pyrophosphatase phosphodiesterase (ENPP) 1 polymorphism with subcutaneous adiposity in a South African Black population. EAMJ. 2018;95(4):1474-783. 
24 Feld S, Hirschberg R. Growth hormone, the insulin-like growth factor system, and the kidney. Endocr Rev. 1996 Oct;17(5):423-80.

25 O'Brown ZK, Van Nostrand EL, Higgins JP, Kim SK. The inflammatory transcription factors NFkB, STAT1 and STAT3 drive age-associated transcriptional changes in the human kidney. PLoS Genet. 2015 Dec;11(12): e1005734.

26 Horita S, Nakamura M, Suzuki M, Satoh N, Suzuki A, Seki G. Selective insulin resistance in the kidney. Biomed Res Int. 2016;2016:5825170.

27 Herrington WG, Smith M, Bankhead C, Matsushita K, Stevens S, Holt T, et al. Body-mass index and risk of advanced chronic kidney disease: prospective analyses from a primary care cohort of 1.4 million adults in England. PLoS One. 2017;12(3):e0173515.

28 Schultheiss UT, Daya N, Grams ME, Seufert J, Steffes M, Coresh J, et al. Thyroid function, reduced kidney function and incident chronic kidney disease in a community-based population: the atherosclerosis risk in communities study. Nephrol Dial Transplant. 2017 Nov 1;32(11):1874-81.

29 Bairey Merz CN, Dember LM, Ingelfinger JR, Vinson A, Neugarten J, Sandberg KL, et al. Sex and the kidneys: current understanding and research opportunities. Nat Rev Nephrol. 2019 Oct 4;15(12):776-83.

30 Keene KL, Mychaleckyj JC, Smith SG, Leak TS, Perlegas PS, Langefeld CD, et al. Association of the distal region of the ectonucleotide pyrophosphatase/phosphodiesterase 1 gene with type 2 diabetes in an African-American population enriched for nephropathy. Diabetes. 2008;57(4):1057-62.

31 Genomes Project Consortium; Auton A, Auton A, Brooks LD, Durbin RM, Garrison EP, Kang HM, et al. A global reference for human genetic variation. Nature. 2015 Oct 1;526(7571):68-74.

32 Moura RR, Coelho AV, Balbino VQ, Crovella S, Brandão LA. Meta-analysis of Brazilian genetic admixture and comparison with other Latin America countries. Am J Hum Biol. 2015 Sep-Oct;27(5):674-80.

33 Bryc K, Durand EY, Macpherson JM, Reich D, Mountain JL. The genetic ancestry of African Americans, Latinos, and European Americans across the United States. Am J Hum Genet. 2015 Jan 8;96(1):37-53.

34 Curtis VF, Cartwright IM, Lee JS, Wang RX, Kao DJ, Lanis JM, et al. Neutrophils as sources of dinucleotide polyphosphates and metabolism by epithelial ENPP1 to influence barrier function via adenosine signaling. Mol Biol Cell. 2018 Nov 1;29(22):2687-99.

35 Lodish H, Berk A, Zipursky SL, Matsudaira, Darnell . Transport across epithelia. In: Freeman WH, editor. Molecular cell biology. 4th ed. New York: Media Connected; 2000.

36 Uhlen M, Fagerberg L, Hallstrom BM, Lindskog C, Oksvold P, Mardinoglu A, et al. Proteomics. Tissue-based map of the human proteome. Science. 2015 Jan 23;347(6220):1260419.

37 Kirk A, Campbell S, Bass P, Mason J, Collins J. Differential expression of claudin tight junction proteins in the human cortical nephron. Nephrol Dial Transplant. 2010 Jul;25(7):2107-19.

38 Liu BC, Tang TT, Lv LL, Lan HY. Renal tubule injury: a driving force toward chronic kidney disease. Kidney Int. 2018 Mar;93(3):568-79.

39 Jankowski M, Piwkowska A, Rogacka D, Audzeyenka I, Janaszak-Jasiecka A, Angielski S. Expression of membrane-bound NPP-type ecto-phosphodiesterases in rat podocytes cultured at normal and high glucose concentrations. Biochem Biophys Res Commun. 2011 Dec 9;416(1-2):64-9.

40 Beck GR Jr, Moran E, Knecht N. Inorganic phosphate regulates multiple genes during osteoblast differentiation, including Nrf2. Exp Cell Res. 2003 Aug 15;288(2):288-300.

41 Yamawaki K, Kanda H, Shimazaki R. Nrf2 activator for the treatment of kidney diseases. Toxicol Appl Pharmacol. 2018 Dec 1;360:30-7.

42 Chauhan G, Spurgeon CJ, Tabassum R, Bhaskar S, Kulkarni SR, Mahajan A, et al. Impact of common variants of PPARG, KCNJ11, TCF7L2, SLC30A8, HHEX, CDKN2A, IGF2BP2, and CDKAL1 on the risk of type 2 diabetes in 5,164 Indians. Diabetes. 2010 Aug;59(8):2068-74.

43 Levey AS, Inker LA. Assessment of glomerular filtration rate in health and disease: a state of the art review. Clin Pharmacol Ther. 2017 Sep;102(3):405-19.

44 Pottel H. Measuring and estimating glomerular filtration rate in children. Pediatr Nephrol. 2017 Feb; 32(2): 249-63. 